attempt to trace the influence of Milton's eyesight and of his blindness on his poetical achievements is an idle task, for Milton, whose soul was like a star that dwelt apart, is like Shakespeare, free-though others abide our question.

\title{
REFERENCES
}

1. Sonnet XIX,

2. Sonnet XXII.

3. Paradise Lost, III, 21-26.

4. Defensio Secunda Pro Populo Anglicano

5. Letter to Philaras, available in D. Masson's Life of Milton, Vol. IV, p. 640.

6. The earliest Life of Milton. Edited by E. S. Parsons, Vol. X, Colorado College Studies, 1903.

7. Philips, Edward-Life of Milton. Available in W. Godwin's Lives of E. and J. Philips. 1815.

8. Aubrey, J.-Life of Milton. Available in Alfred Stern's Milton und seine Zeit, Vol. I, Appendix, 1877.

9. March, J. F.-On the engraved portraits of Milton. 1860.

10. The portraits of John Milton exhibited at Christ's College Tercentenary Celebration. 1908. (Souvenir)

11. Masson, D.-Life of Milton. Vol. IV., p. 427.

12. Stern, Alfred.-Milton und seine Zeit, 1879, note on p. 93, Vol. III.

13. Hirschberg, J.-Geschichte der Augenheilkunde in Graefe-Saemisch Handbuch der Augenheilkunde 2te Auflage. Vol. XIV, 4 Abteil., 3 Buch, p. 146, footnote 2

14. American Encyclopedia of Ophthalmology. Vol. X, Article on Milton.

15. Dufour, M.-A note on Milton's Blindness. The Ophthalmoscope, 1909. Vol. VII, p. 599.

16. Saurat, D. and Cabannes, C. - Milton devant la Médecine, Journal de Médecine de Bordeaux, 1924, p. 7 (also as appendix in Saurat, D., Milton: Man and Thinker, 1925.)

17. Mutschmann, H.-Milton und das Licht. Beiblatt zu Anglia, XXX, 11/12, 1920. Der andere, Milton. 1920.

18. Mutschmann, H.-Milton's eyesight and the chronology of his work (in English in Eestu. Vabarügi Tartu, etc. B.5, Dorpat, 1924.)

19. Squires, N. P.-In Modern Language Notes. IX, p. 454, 1894.

20. Lawrence, W. -Treatise on diseases of the eyes. 1832.

21. Mackenzie, W.-A practical treatise on the diseases of the eyes. p. 891.1840.

\section{A REPORT ON THE USE OF VITAMIN "A" IN CONJUNCTION WITH ULTRA-VIOLET LIGHT IN OPHTHALMIC DISEASES}

BY

\section{J. D. Magor Cardell}

ASSISTANT SURGEON, CENTRAL LONDON OPHTHALMIC HOSPITAL

ANY remedy or therapeutic measure which is acclaimed, especially in the daily press, as a panacea, should be approached with suspicion. For this reason much harm has been done to the legitimate use of ultra-violet light in the minds of reasonable people by those advocates who have proclaimed it as the cure for any and every bodily ailment. 
Such a condition of affairs is largeiy due to the fact that for some years this form of treatment has been in the hands of unqualified persons; but, if it is recognised that it has, in common with any other specialised form of treatment, a well-defined and limited application, it will then be given its proper place among modern methods of ophthalmic treatment.

That it has a definite application may be seen from the following report on cases which have been attended in the ultra-violet light clinic of the Central London Ophthalmic Hospital.

This clinic has now been working for three years and records of 181 cases are available for analysis. The clinic was inaugurated by Miss Ida Mann and was under her supervision during the first year when 64 cases were treated. I am indebted to her for permission to use the records she then obtained.

The lamp used is a carbon-arc which gives a steady output of ultra-violet rays. In the case of mercury vapour lamps the output diminishes as the lamp gets older, so that without frequent control, exposures necessitating some delay, the dosage cannot be accurately measured by the clock.

As a preliminary, those cases suffering from arteriosclerosis, Bright's disease, cardio-vascular lesions, glycosuria, menorrhagia, and pulmonary tuberculosis, are excluded as such are very frequently harmed by ultra-violet light.

General exposures of increasing duration are given tri-weekly in serial rotation so that the same skin surface is not exposed on two successive visits. Signs of increased temperamental irritability, insomnia, persistent loss of weight, nausea, anorexia, and a raised temperature 24 hours after exposure, indicate an over dosage, and should any of these occur the treatment is stopped.

All cases treated in this clinic are examined at least once a fortnight when a note is made of the condition and progress of the disease.

At the end of two years it was discovered that if improvement were to be obtained from this treatment it was noticeable at the end of 12.9 exposures (this figure agrees with that of 12.5 found by an independent observer working under similar conditions el ewhere and without previous collaboration), so patients are now given "courses" of 15 exposures. Since after a large number of exposures the skin becomes tolerant to the rays, and since too many or too prolonged exposures result in debility and depression, these "courses" are punctuated by a month's interval when no light treatment is given.

As a result of this regime there has been a saving of the patient's time and the hospital's purse, and a larger number of patients have been accommodated in the clinic - in a word, greater efficiency.

During the last year Vitamin A has been given to the patients concurrently with the ultra-violet light. This vitamin has been 
shown by Green and Mellanby to have anti-infective properties, and the tables below show the comparative results obtained with and without this addition to the treatment. The action of the vitamin is more pronounced when given in conjunction with an oil or in an oily vehicle.

The patients all state that they feel better "in themselves" for the treatment-eat better, sleep better, and in most cases put on weight. Very few cases fail to attend regularly, showing that they appreciate the benefit derived.

The best results have been obtained in phlyctenular ophthalmia, hordeola, episcleritis, corneal ulcers and tuberculous iritis. In other conditions the results are good but not, to my mind, convincing: that is to say, though improvement has taken place it is difficult to determine whether it has been due to the ultra-violet light or would have occurred as a result of the ordinary routine treatment employed at the same time.

It will be noticed that the conditions mentioned above as being benefited by the rays occur superficially or in the anterior segment of the eye, while those more deeply seated, such as vitreous opacities, choroiditis, optic neuritis, etc., do not seem to improve to an extent which justifies the time given up to the treatment by the patient.

The more cases that are treated with ultra-violet light, the more surely can those cases which will derive benefit be selected, the more efficiently will a light clinic be administered, and the more will the true value of this treatment be appreciated.

\section{TABLE I.}

Comparison between 53 Cases which Received Vitamin "A" AND 86 CASES WITHOUT THIS ADDITION.

a With Vitamin " $A$ "

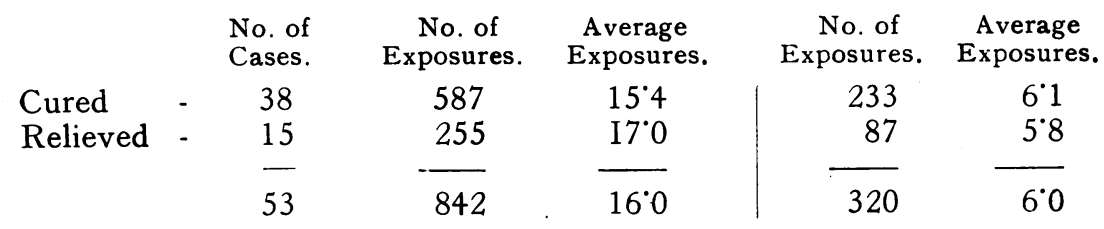

$b$ Without Vitamin " $A$ "

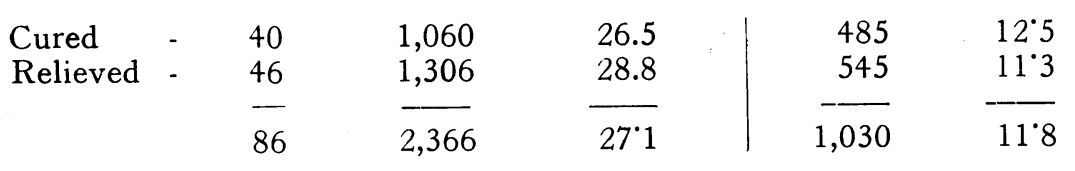

Point at which improvement first recorded. 
TABLE II.

Comparison of Selected Diseases.

\begin{tabular}{|c|c|c|c|c|c|c|c|c|}
\hline \multirow{3}{*}{ Disease. } & \multicolumn{4}{|c|}{ With Vitamin " $A$ " } & \multicolumn{4}{|c|}{ Without Vitamin "A" } \\
\hline & \multicolumn{2}{|c|}{ CURED } & \multicolumn{2}{|c|}{ RELiEved } & \multicolumn{2}{|c|}{ CuRED } & \multicolumn{2}{|c|}{ RELIEVED } \\
\hline & Cases & Exposures & Cases & Exposures & Cases & Exposures & Cases & Exposures \\
\hline Conjunctivitis- & 3 & 41 & 1 & 15 & 2 & 111 & 1 & 12 \\
\hline Corneal Ulcer- & 5 & 69 & 2 & 24 & 10 & 140 & 7 & 114 \\
\hline Episcleritis & 3 & 58 & - & 一 & 4 & 92 & 2 & 51 \\
\hline $\begin{array}{l}\text { Interstitial } \\
\text { Keratitis - }\end{array}$ & 2 & 37 & 3 & 61 & 2 & 53 & 8 & 194 \\
\hline $\begin{array}{l}\text { Phlyctenular } \\
\text { Ophthalmia - }\end{array}$ & 11 & 125 & 3 & 39 & 10 & 256 & 6 & 106 \\
\hline A tot & $\begin{array}{r}\text { of } 3 \\
\mathrm{ex}\end{array}$ & $\begin{array}{l}3 \text { cases } \\
\text { osures. }\end{array}$ & & & & $\begin{array}{l}\text { otal of } 5 \\
1,131 \text { ex }\end{array}$ & $\begin{array}{l}2 \text { cas } \\
\text { pcsur }\end{array}$ & $\begin{array}{l}\text { es had } \\
\text { es. }\end{array}$ \\
\hline
\end{tabular}

MRS. C., aged 26 years, a patient of Dr. Armour, of Woodhall Spa, was seen by us on January 24, 1930.

She complained that two years ago she had noticed some defect in vision in her left eye and that this had gradually become worse. Six months ago she noticed that this eye had become somewhat prominent and that the prominence had gradually increased to its present state. She made no further complaint at all.

On examination, it was seen that this left eye was proptosed to the extent of about $0.75 \mathrm{~cm}$. The movements were full in every direction and no diplopia could be elicited. There were about five dioptres of hypermetropia and vision with a plus 5.5 D.sph. was 6/12. There was a mild, though quite definite degree of papilloedema as shown by fullness of the vessels and blurring of the disc margins, 